\title{
JORGE PAVEZ OJEDA. LABORATORIOS ETNOGRÁFICOS. LOS ARCHIVOS DE LA ANTROPOLOGÍA EN CHILE(1880-1980). Ediciones Universidad Alberto Hurtado, 2015, 595 pág.
}

Escribir, d-escribir, construir relatos, hablar sobre otros teóricamente desde una perspectiva de esos otros. Para conocer mejor, para saber con más detalle quiénes son, qué hacen, por qué lo hacen. Hablar de ellos/as, sin mencionar demasiado el nosotros, desde el marco del reconocimiento, la diversidad, el valor de la diferencia cultural (de la material, mejor no hablar). Entonces, desde allí también entender, o comprender, que en definitiva incorpora ya de facto y sin discusión la noción de interpretarlos/as, que durante algún tiempo tendía a incomodar. Todo eso con el tiempo inevitablemente nos conduce a unos archivos, verdaderos receptáculos sagrados que vuelven posible esa inclaudicable manía del mundo occidental por hacer del tiempo un valor tangible, mensurable y poderoso, o más bien, necesario para los poderosos. Porque allí, en definitiva, en esos escribires acumulados se aloja una forma de organización de un saber, nos señala Pavez, silenciosa o escondida en los pliegues de páginas vetustas y poco visitadas.

Este es el punto de partida de los laboratorios etnográficos. Un punto que se acompaña de una guinda particular que corona e imprime el sabor a todo el resto de ingredientes del pastel, cual es la noción de colonialidad. Por eso, la guinda se enuncia tempranamente, en el Prefacio, como para decirnos que aquel es el contexto y que, como sospechamos, el contexto es fundamental. Para entender qué se dijo, por qué se dijo y cómo se dijo. También el quién lo dijo, pero eso ya es un acto de representación, el quién entra dentro del tema de las vocerías; importantes, pero no determinantes.

Otra cosa que el autor nos aclara de entrada es que fueron años siguiendo intermitentemente pistas, aprovechando tiempos por aquí y por allá dentro de otras tareas emprendidas, sin saber que algún día aquel paciente deambular por bibliotecas, archivos, discusiones y puntos ciegos, acabaría por decantar en este Laboratorios etnográficos. Nada banal, si se considera que este no es un libro 'por encargo', ni tampoco un objeto hecho a la medida de sumar puntos para subir la calificación académica del autor. O sea, no deriva de una corriente utilitaria. De hecho, este es uno de esos libros que no se intuyó desde sus inicios, ni se diagramó antes de saber que iba a contener. Fue libro a partir del caudal de información recopilada a través de años tirando de un hilo que no acaba nunca, el de las preguntas en torno a la cultura como construcción cultural.

Interesante. Porque aquí un no-antropólogo encuentra datos, pero igualmente relatos, vínculos y relecturas que nos hacen invariablemente volver sobre los primeros y su compleja relación con la idea de verdad. Y al neófito le puede gustar por los hallazgos mencionados, pero además por el interés en analizar una forma de hacer ciencia desde la representación de la otredad y sus múltiples calles laberínticas. Por lo mismo, para los antropólogos ya hechos 
y formados, se vuelve todavía más interesante todo esto, porque nos pone frente a un espejo que deconstruye una historia que no visitamos mucho. Y no lo hace por simple afán, sino para desde una perspectiva otra, mostrar los pliegues, las junturas, las distintas técnicas de coser y hacer nudos que una ciencia proyectada como ventrílocua ha ido consolidando en su andar. Todo muy antropológico, por cierto.

Si escribir es un recurso hasta hoy ineludible para una disciplina como la antropología, proponerse analizar cómo ha operado ese no ingenuo ejercicio de escribir desde ella, en tanto forma de organización de un saber, sí que es una tarea ardua. Posiblemente, y tal como lo señala el propio autor, su trabajo debe haber deambulado entre la fascinación y el rechazo, descifrando hallazgos en tanto "construcciones", u operaciones de saber que siempre estarán atadas a sus contextos y sus momentos, en las que cuesta mantenerse al margen y no desarrollar opinión. Sin duda, haber tenido la curiosidad inicial tan marcada le permitió a su vez tener un conjunto de preguntas que el tiempo ayudó a ir aclarando, acabando por ser estas seguramente un sostén de las pesquisas, entremedio de libros polvorientos, documentos inconsultos quizás desde cuando, reseñas poco vistas en bibliotecas que, puede que en más de una ocasión, no supieran lo que tenían escondidas en sus bodegas.

¿Qué nos deja entonces este Laboratorios etnográficos? En principio, un caudal de cruces y relaciones que ponen luces sobre el cómo se ha ido construyendo -y legitimando-, una disciplina en tanto campo de saberes sobre 'lo cultural' en Chile. Con sus momentos, sus vínculos, sus intereses y proyecciones, que a su vez nos llevan hacia sus límites, nichos, operaciones y atributos.
Antes incluso que fuera una tierra habitada por antropólogos, cuando los investigadores-recopiladores en otra cosa. Y ello nos deja datos, pero también reflexiones, estas últimas a manera de hilvanamientos que se van asomando mientras se mueve el zoom, a veces para acercarse, otras para tomar distancia y ver contextos.

Pero seamos justos. Aquel no es el único mérito, ni el más destacable. Porque si algo resulta atractivo en este libro es el caudal de fórmulas y engranajes que ofrece para hacernos releer lo que ya dábamos por sentado, allí donde pocos se asomaban a mirar. En este sentido, no puede ser más sugerente el inicio mismo del libro, donde nos relata sucintamente una variación capital realizada en algún momento de sus pesquisas y que resulta ser determinante para todo lo que viene después: el cambio de la categoría de gabinete por la de laboratorio. Es que el gabinete es un lugar seguro donde es posible sentarse a rellenar cronologías en base a las cuales establecer tendencias y posicionar referencias. Instructivo, ilustrativo. Pero el laboratorio ya es otra cosa, es aquello que te lleva por los derroteros de la producción de los saberes interpeladas por su contexto; es el lugar donde se juntan investigadores y dispositivos de poder, instrumentos con inscriptores (personas y aparatos) orientados a la visualización de un saber que teóricamente perfecciona lo habido. Son lugares que, se asume, "construyen" antes que solo "describen". Asunto de primer orden de importancia al momento de buscar escribir sobre -no 'la'historia de la antropología en Chile. Ya lo dice el mismo autor:

"En el caso de los laboratorios etnográficos, estos lugares son territorios completos sometidos a procesos de ocupación estatal y de colonización, y sus experimentos son las profundas trasformaciones de las 
sociedades intervenidas por el proceso de expoliación colonialista" (28).

Réquiem. Adiós ingenuidad antropológica. Detengamos ya la maquinaria que busca justificar la antropología únicamente desde su compromiso con quienes padecen la historia. Olvidémonos de aquellas aseveraciones taxativas que buscan imponer a través de supuestas verdades presentadas como hallazgos una superioridad moral académica que puede renegar de otras formas de construcción de conocimiento. $Y$ entremos a leer un testimonio de quien anduvo entrometiéndose en una mente colectiva y todo su caudal de juicios, vacilaciones, intereses, deudas, anhelos, alianzas, producción de secretos, antagonismos, transacciones y acuerdos que suponía concretar un quehacer científico que pudiera ser considerado como tal por los predecesores y que se sustenta, sobre todo, en un ejercicio de producir, legitimar y consolidar "una versión consistente de lo que se decide llamar "cultura"' (40).

Y así, a través de un lenguaje que no reniega de su cercanía con los estudios coloniales y la antropología posmoderna, o los estudios de sociología de la cultura, Pavez nos lleva por los derroteros de un análisis que no puede sino ser crítico, no de la antropología como proyecto académico, político y ético, sino de su ejercicio in situ. $\mathrm{O}$ sea, desde un proyecto inserto en un contexto y llevado a cabo por personas -muchas veces transformados en personajes por las circunstancias. Todo ello desde la relectura de las evidencias conocidas y ya aceptadas como verdaderas, lo que implica la ampliación de la mirada para observar los eventos microscópicos, o ciertamente la atención a los contextos globales para releer las búsquedas de posicionamientos particulares. Todo para mostrarnos que antropólogos y antropólogas somos parte de este mismo mundo. $Y$ que somos parte de las mismas redes y flujos de construcción de realidad que nuestros vecinos que ejercen en el día a día, otros oficios, otros saberes. De paso, un viejo imperativo disciplinario es reflotado: no puede ser casualidad que la antropología, tal como la conocemos hoy en día, haya nacido y se haya desarrollado en el mundo de la cultura occidental.

Solo para precisar, para quienes les interesa la formalidad: el libro posee una estructura clara. La introducción nos propone los anclajes que construirán -paradójicamente a través de un ejercicio de deconstrucción-, los soportes que unirán las distintas piezas y permitirán conformar aquel relato sobre algunos relatos que hablan de cómo la antropología chilena construyó la otredad. Pero en el fondo lo que hace es contarnos el secreto de su afán, cual es, desclasificar los procesos de clasificación que permitieron consolidar la antropología chilena como una entidad tangible. Siguiendo lo que nos señalaran hace más de un siglo $\mathrm{E}$. Durkheim y M. Mauss, el autor funciona en base a la premisa de que las cosas no existen hasta que son nombradas. Y cuando lo son, pasan a formar parte de una realidad intrínsecamente dependiente del contexto en el que emergió aquella necesidad de nombramiento. De ahí en más entonces, pasada la introducción en tanto puesta a punto, la invitación es a realizar un viaje por distintos momentos, situaciones y personas que han marcado el desarrollo disciplinar. Y ahí están desde los momentos fundacionales de la antropología chilena ligada a las "ciencias del espíritu" alemanas, proceso encabezado por Rodolfo Lenz y Max Uhle, al cual de pronto se nos adhiere Martín Gusinde. Con toda la retórica de creación de un corpus 
indigenista republicano que supere el hispanismo católico y permita dar con un "espíritu de pueblo". También se visita la obra de Tomás Guevara y su colosal "operación historiográfica", inserta dentro de un contexto marcadamente colonialista, que no obstante contribuyó a la formación del primer movimiento político mapuche en la era reduccional. Igualmente presentes están los archivos que nos hablan de momias, museos, compras y clases sociales que vendrían a comprobar "que el dispositivo etnológico de visibilización histórica de la alteridad indígena en Chile ha sido siempre una cuestión determinada por las formas de enunciación de la soberanía nacional por el colonialismo chileno" (486). Cuestión que queda despejada ya con la revisión documental de la figura de Gustavo Le Paige y su paso por Atacama.
La intención, dicho está, no es agotar una instancia, menos completarla o zanjar sus cualidades principales. Lo que se nos propone es una mirada a ciertos archivos que hablan de cómo se hizo el juego de representaciones, en base a revisar documentación de ciertos representantes. $Y$ es esta una mirada que propone inevitablemente una relectura. No para decirnos qué es lo más importante ni lo menos importante, acto cargado de soberbia y superioridad colonialista. Pero quizá sí para que aprendamos y aceptemos que somos parte de la trama del mundo y que, por ello, las categorías con que manejamos nuestro derrotero histórico de la disciplina son relativas y arbitrarias, o sea, dependientes de colectivos que entran en relaciones, de poder y de las otras (si es que las hay). No podía ser de otra manera si de lo que hablamos es de antropología, antropología chilena.-

Rodrigo Herrera O., Profesor Magister en Antropología, Universidad Academia de Humanismo Cristiano, Santiago - Chile 